\title{
Helical structure of linear homopolymers
}

\section{Sorana D. BOLBOACA ${ }^{1, a}$ and Lorentz JÄNTSCHI ${ }^{2,3, b^{*}}$}

${ }^{1}$ Department of Medical Informatics and Biostatistics, Iuliu Haţieganu University of Medicine and Pharmacy, 400349 Cluj-Napoca, Romania

${ }^{2}$ Department of Physics and Chemistry, Technical University of Cluj-Napoca, Muncii Blvd., no. 103-105, 400641 Cluj-Napoca, Romania

${ }^{3}$ Chemistry Doctoral School, Babeş-Bolyai University, Arany János Str., no. 11, 400028 ClujNapoca, Romania

a sbolboaca@umfcluj.ro, b lorentz.jantschi@gmail.com

Keywords: Helical structure, Computational study, Polymers.

\begin{abstract}
The aim of our research was to conduct a computational study on helical geometries of several homopolymers. Simple helix of polymers with seventeen (poly(lactic acid)) or eighteen (poly(1-chloro-trans-1-butenylene), poly(1-methyl-trans-1-butenylene), poly(1,4,4-trifluoro-trans1-butenylene), polyacrylonitrile and respectively polychlorotrifluoroethylene) monomers were investigated. The $\mathrm{X}, \mathrm{Y}$, and $\mathrm{Z}$ coordinates obtained after optimization of the geometry of polymers were used as input data to identify the rotation and translation of the coordinates and respectively the coefficient of the helix. The values of interest were calculated by minimization of residuals using two different protocols. The first protocol investigated the whole polymer by imposing (step 1) or not (step 2) a fixed value of the helix coefficient. The second protocol investigated by minimization of residuals if the monomer (one or two) from each end of the polymer is or not an outlier of the helical geometry of the polymer.
\end{abstract}

\section{Introduction}

The conformation of natural polymers goes back in 1937 when the helical structure of $\alpha$-amylose was proposed by Hanes [1, 2] and further investigated by Freudenbers [3]. Linus Pauling and Robert B. Corey [4] showed in the 1950s that proteins chain form by monomeric units of proteins represented by amino-acids twists into a helix ( $\alpha$-helix) called secondary structure. These discoveries along with the identification of double-helical structure of DNA by James Watson and Francis Crick [5] were major breakthroughs.

Simulations studies conducted on some synthetic polymers (e.g. m-terphenyl-based $\pi$-conjugated polymer [6], poly(ethylene glycol) (PEG) [7], poly(ethylene imine) (PEI) [8], squaraine polymers [9]) shown their tendency to form helixes.

The helical shape translation of biopolymers in synthetic materials could lead to identification of materials with desired properties.

Ten linear chained homopolymers (polymers made by identical units) were subject to the investigation of shaping in a helix form. The aim of the study was to identify the helix parameters where helix shapes appears.

\section{Polymers Generic Structures and Their Main Characteristics}

The repeated sequence, abbreviation when existent, name and the feasibility to provide helix [10] are given in Table 1. 
Table 1. Generic structure of polymers

\begin{tabular}{|c|c|c|}
\hline No & Structure & Formula, abbreviation, name and remarks \\
\hline$\# 1$ & & $\begin{array}{l}\left(\mathrm{C}_{2} \mathrm{H}_{4} \mathrm{O}\right)_{\mathrm{n}} \\
\text { PEG } \\
\text { Name: poly(ethylene glycol) } \\
\text { Likely to provide helix: No, is purely linear }\end{array}$ \\
\hline$\# 2$ & & $\begin{array}{l}\left(\mathrm{C}_{2} \mathrm{H}_{5} \mathrm{~N}\right)_{\mathrm{n}} \\
\text { PEI } \\
\text { Name: polyethyleneimine } \\
\text { Likely to provide helix: No, is purely linear }\end{array}$ \\
\hline$\# 3$ & & $\begin{array}{l}\left(\mathrm{C}_{3} \mathrm{H}_{4} \mathrm{O}_{2}\right)_{\mathrm{n}} \\
\text { PLA } \\
\text { Name: poly(lactic acid) } \\
\text { Likely to provide helix: Yes, internal helix }\end{array}$ \\
\hline$\# 4$ & & $\begin{array}{l}\left(\mathrm{C}_{6} \mathrm{H}_{9} \mathrm{NO}\right)_{\mathrm{n}} \\
\mathrm{PVP} \\
\text { Name: poly(N-vinyl-pyrrolidone) } \\
\text { Likely to provide helix: Yes, double helix }\end{array}$ \\
\hline$\# 5$ & & $\begin{array}{l}\left(\mathrm{C}_{4} \mathrm{H}_{6}\right)_{\mathrm{n}} \\
\text { Name: poly(trans-1-butenylene) } \\
\text { Likely to provide helix: No, is purely linear }\end{array}$ \\
\hline \#6 & & $\begin{array}{l}\left(\mathrm{C}_{4} \mathrm{H}_{5} \mathrm{Cl}\right)_{\mathrm{n}} \\
\text { Name: poly(1-chloro-trans-1-butenylene) } \\
\text { Likely to provide helix: Yes }\end{array}$ \\
\hline
\end{tabular}




\begin{tabular}{|c|c|c|}
\hline No & Structure & Formula, abbreviation, name and remarks \\
\hline \#7 & & $\begin{array}{l}\left(\mathrm{C}_{5} \mathrm{H}_{8}\right)_{\mathrm{n}} \\
\text { Name: poly(1-methyl-trans-1-butenylene) } \\
\text { Likely to provide helix: Yes }\end{array}$ \\
\hline \#8 & & $\begin{array}{l}\left(\mathrm{C}_{4} \mathrm{H}_{3} \mathrm{~F}_{3}\right)_{\mathrm{n}} \\
\text { Name: poly(1,4,4-trifluoro-trans-1-butenylene) } \\
\text { Likely to provide helix: Yes }\end{array}$ \\
\hline \#9 & & $\begin{array}{l}\left(\mathrm{C}_{3} \mathrm{H}_{3} \mathrm{~N}\right)_{\mathrm{n}} \\
\text { PAN } \\
\text { Name: polyacrylonitrile } \\
\text { Likely to provide helix: Yes, internal helix }\end{array}$ \\
\hline$\# 10$ & & $\begin{array}{l}\left(\mathrm{CF}_{2} \mathrm{CClF}\right)_{\mathrm{n}} \\
\text { PCTFE / PTFCE } \\
\text { Name: polychlorotrifluoroethylene } \\
\text { Likely to provide helix: Yes, internal helix }\end{array}$ \\
\hline
\end{tabular}

Poly(ethylene glycol) or PEG, available in different geometries such as branched (3 to 10 PEG), star (10 to 100 chains) or comb (multiple PEG chains grafted onto a polymer backbone) is a compound with applications in different fields from industry to medicine.

PEGs are used as the basis of laxative [11], excipient in pharmacological products, or delivery systems [12-15]. PEGs are also used as the basis of skin creams [16], toothpaste or as an anti-foaming agent in food [17], and despite the fact that is considered biologically inert and safe can be responsible by contact dermatitis [16].

Polyethyleneimine (PEI) is a synthetic polymer, weakly basic and non-toxic that can take linear, branched or dendrimeric forms [18]. PEIs have been successfully used as drug carriers [19,20], gene delivery system [21,22], or growth inhibitors of microbial species [23] or cancer cells [24].

Poly(lactic acid) (polylactic acid or polylactide, PLA) is a biodegradable polyester obtained from renewable resources [25] and used in 1974 in combination with polyglycolic acid (PGA) as suture materials [26]. Due to biocompatibility and dissolvability in the body, PLA and its co-polymers were used in tissue engineering [27,28], or as carriers for bone morphogenetic proteins [29], in suture materials [30], and delivery systems [31,32]. 
Poly(N-vinyl-pyrrolidone) (polyvidone or povidone, PVP) is a water-soluble synthetic polymer used as a blood plasma substituent due to its hemocompatibility [33]. Poly(N-vinyl-pyrrolidone) nanoparticles have shown potential as drug delivery systems for hydrophobic drugs [34,35].

Poly(trans-1-butenylene), poly(1-chloro-trans-1-butenylene), poly(1-methyl-trans-1-butenylene), and poly(1,4,4-trifluoro-trans-1-butenylene) are polyalkadienes. They have a glass transition temperature ( $\left.\mathrm{T}_{\mathrm{g}} / \mathrm{K}\right)$ from 207 (poly(1-methyl-trans-1-butenylene)) to 238 (poly(1,4,4-trifluoro-trans-1-butenylene)) [36].

Polyacrylonitrile (PAN) is a synthetic, semicrystalline organic polymer resin, first synthesized in 1930 by Dr. Hans Fikentscher and Dr. Claus Heuck [37]. Because is hard, relatively insoluble, and a highmelting material [38], PAN is used to develop carbon fibers by stabilization, carbonization, and graphitization under controlled conditions [39,40]. PAN is also used in development of nanofibers [41,42], microcapsules/microspheres with diverse application (such as foam targets, carbon molecular sieve, cargo storage, or medical instruments) [43], semiconductor PAN powder $\left(10^{-10} \mathrm{~S} / \mathrm{cm}<\right.$ conductivity $<10^{-3} \mathrm{~S} / \mathrm{cm}$ when treated at $285-300^{\circ} \mathrm{C}$ ) [44], or in the treatment of metals [45].

Polychlorotrifluoroethylene (PCTFE or PTFCE) is a thermoplastic chlorofluoropolymer discovered in 1934 by Fritz Schloffer and Otto Scherer [46]. PTFCE is nonflammable, has a high optical transparency, is chemical resistant, and has near-zero moisture absorption and excellent electrical properties [47-49]. The co-deposition of PCTFE (at a concentration less than or equal to $4 \mathrm{~g} / \mathrm{l}$ ) into Ni-W coating proved a feasible manufacturing of fluid lubricant [50]. The conductivity of PTFCE was double by treatment with nano-size copper iodide [51]. In pharmaceutical and medical industry, the PCTFE is used for packaging [52,53]. PCTFE find its application in many sectors such as chemical industry, manufacturing, electronics, architecture, energy, health and domestic sectors [54].

\section{Helix Coefficients by Minimization of Residuals}

The problem of finding the helixes determined by the atoms positions was investigated on those structures presented in Table 1 that are likely to provide a helix. Finding the helixes on these polymers is essentially a double problem. The proper rotations (eq1) and translation (eq2) of the coordinate system in such way that the helix to be aligned to the z-coordinate must be identify before and after identification of the helix (eq3).

$$
\begin{aligned}
& {\left[\begin{array}{l}
\mathrm{x}_{1} \\
\mathrm{y}_{1} \\
\mathrm{z}_{1}
\end{array}\right]=\left[\begin{array}{lll}
\cos \left(\mathrm{a}_{0}\right) & \sin \left(\mathrm{a}_{0}\right) & 0 \\
-\sin \left(\mathrm{a}_{0}\right) & \cos \left(\mathrm{a}_{0}\right) & 0 \\
0 & 0 & 1
\end{array}\right] \cdot\left[\begin{array}{l}
\mathrm{x}_{0} \\
\mathrm{y}_{0} \\
\mathrm{z}_{0}
\end{array}\right]} \\
& {\left[\begin{array}{l}
\mathrm{x}_{2} \\
\mathrm{y}_{2} \\
\mathrm{z}_{2}
\end{array}\right]=\left[\begin{array}{lll}
\cos \left(\mathrm{a}_{1}\right) & 0 & -\sin \left(\mathrm{a}_{1}\right) \\
0 & 1 & 0 \\
\sin \left(\mathrm{a}_{1}\right) & 0 & \cos \left(\mathrm{a}_{1}\right)
\end{array}\right] \cdot\left[\begin{array}{l}
\mathrm{x}_{1} \\
\mathrm{y}_{1} \\
\mathrm{z}_{1}
\end{array}\right]} \\
& {\left[\begin{array}{l}
\mathrm{x}_{3} \\
\mathrm{y}_{3} \\
\mathrm{z}_{3}
\end{array}\right]=\left[\begin{array}{lll}
1 & 0 & 0 \\
0 & \cos \left(\mathrm{a}_{2}\right) & \sin \left(\mathrm{a}_{2}\right) \\
0 & -\sin \left(\mathrm{a}_{2}\right) & \cos \left(\mathrm{a}_{2}\right)
\end{array}\right] \cdot\left[\begin{array}{l}
\mathrm{x}_{2} \\
\mathrm{y}_{2} \\
\mathrm{z}_{2}
\end{array}\right]}
\end{aligned}
$$




$$
\begin{aligned}
& {\left[\begin{array}{l}
\mathrm{x}_{4} \\
\mathrm{y}_{4} \\
\mathrm{z}_{4}
\end{array}\right]=\left[\begin{array}{l}
\mathrm{x}_{3} \\
\mathrm{y}_{3} \\
\mathrm{z}_{3}
\end{array}\right]-\left[\begin{array}{l}
\mathrm{a}_{3} \\
\mathrm{a}_{4} \\
\mathrm{a}_{5}
\end{array}\right]} \\
& \left\{\begin{array}{l}
\mathrm{x}_{4}=\mathrm{a}_{7} \cdot \sin \left(\mathrm{a}_{6} \cdot \mathrm{t}\right) \\
\mathrm{y}_{4}=\mathrm{a}_{8} \cdot \cos \left(\mathrm{a}_{6} \cdot \mathrm{t}\right) \\
\mathrm{z}_{4}=\mathrm{a}_{9} \cdot \mathrm{t}
\end{array}\right.
\end{aligned}
$$

where $\left(\mathrm{x}_{0}, \mathrm{y}_{0}, \mathrm{z}_{0}\right)$ are the raw Cartesian coordinates of the atoms belonging to the helix, $\left(\mathrm{x}_{1}, \mathrm{y}_{1}, \mathrm{z}_{1}\right),\left(\mathrm{x}_{2}\right.$, $\left.\mathrm{y}_{2}, \mathrm{z}_{2}\right)$ and $\left(\mathrm{x}_{3}, \mathrm{y}_{3}, \mathrm{z}_{3}\right)$ are new Cartesian coordinates obtained through elementary rotations, and $\left(\mathrm{x}_{4}, \mathrm{y}_{4}\right.$, $\left.\mathrm{z}_{4}\right)$ includes a translation. In eq1-eq3, $\mathrm{a}_{\mathrm{i}}(0 \leq i \leq 9)$ are unknown coefficients $\left(\mathrm{a}_{0}, \mathrm{a}_{1}\right.$ and $\mathrm{a}_{2}$ are angles of rotation; $\mathrm{a}_{3}, \mathrm{a}_{4}$ and $\mathrm{a}_{5}$ are scalars of a translation; $\mathrm{a}_{6}, \mathrm{a}_{7}, \mathrm{a}_{8}$ and $\mathrm{a}_{9}$ are the helix parameters; for circularbased helixes $\mathrm{a}_{7}=\mathrm{a}_{8}$ ), and $t$ is the changing parameter defining the evolution of the helix.

The helix is rotated and translated such that its $x O y$ projection is a circle when $\mathrm{a}_{7}=\mathrm{a}_{8}$ while $\mathrm{a}_{7} \neq \mathrm{a}_{8}$ provides an ellipse. The main difficulty is given that starting roughly from atoms coordinates $\left(\mathrm{x}_{0}, \mathrm{y}_{0}, \mathrm{z}_{0}\right)$, all coefficients (from $\mathrm{a}_{0}$ to $\mathrm{a}_{9}$ ) must be identified at once.

The problem defined by the eq1 to eq3 is a problem of optimization. If $n$ represents consecutive points (atoms positions) from the polymer converged as helix, the residual sum $\Sigma_{1 \leq i \leq n} \mathrm{f}_{0}$ should be minimized $\left(\mathrm{f}_{0}\right.$ in eq $\left.4, \mathrm{t} \leftarrow \mathrm{i}\right)$.

$$
\mathrm{f}_{0}=\Sigma\left\{\left[\mathrm{a}_{7} \sin \left(\mathrm{a}_{6} \cdot \mathrm{i}\right)-\mathrm{x}_{4}(\mathrm{i})\right]^{2}+\left[\mathrm{a}_{8} \cos \left(\mathrm{a}_{6} \cdot \mathrm{i}\right)-\mathrm{y}_{4}(\mathrm{i})\right]^{2}+\left[\mathrm{a}_{9} \mathrm{i}-\mathrm{z}_{4}(\mathrm{i})\right]^{2}\right\}
$$

Since some of the unknowns are inside of periodic functions (especially concerns should be taken for $\mathrm{a}_{6}$ ), it is essential that the starting values of the coefficients to be good.

In the case of a double helix, the eq3 can be changed to include a double time-dependence (eq5).

$$
\left\{\begin{array}{l}
\mathrm{x}_{4}=\mathrm{a}_{7} \cdot \sin \left(\mathrm{a}_{6} \cdot \mathrm{t}\right)+\mathrm{a}_{11} \cdot \sin \left(\mathrm{a}_{10} \cdot \mathrm{t}\right) \\
\mathrm{y}_{4}=\mathrm{a}_{8} \cdot \cos \left(\mathrm{a}_{6} \cdot \mathrm{t}\right)+\mathrm{a}_{12} \cdot \cos \left(\mathrm{a}_{10} \cdot \mathrm{t}\right) \\
\mathrm{z}_{4}=\mathrm{a}_{9} \cdot \mathrm{t}
\end{array}\right.
$$

Going back to the problem of minimization (eq4), for fixed values of the $\mathrm{a}_{0}, \mathrm{a}_{1}, \mathrm{a}_{2}, \mathrm{a}_{6}$ (and $\mathrm{a}_{10}$ for eq5) coefficients, the problem may be simplified (by embedding eq3 or eq5 in eq4) to correspond to triple linear regression (eq6 for embedding eq3 in eq4; for embedding eq5 in eq4 is similar).

$$
\begin{aligned}
& 0=\frac{\partial \mathrm{f}_{1}}{\partial \mathrm{a}_{3}}=\frac{\partial \mathrm{f}_{1}}{\partial \mathrm{a}_{7}}, \mathrm{f}_{1}=\sum_{\mathrm{i}=1}^{\mathrm{n}}\left(\mathrm{x}_{3}(\mathrm{i})-\mathrm{a}_{3}-\mathrm{a}_{7} \cdot \sin \left(\mathrm{a}_{6} \cdot \mathrm{i}\right)\right)^{2} \\
& 0=\frac{\partial \mathrm{f}_{2}}{\partial \mathrm{a}_{4}}=\frac{\partial \mathrm{f}_{2}}{\partial \mathrm{a}_{8}}, \mathrm{f}_{2}=\sum_{\mathrm{i}=1}^{\mathrm{n}}\left(\mathrm{y}_{3}(\mathrm{i})-\mathrm{a}_{4}-\mathrm{a}_{8} \cdot \cos \left(\mathrm{a}_{6} \cdot \mathrm{i}\right)\right)^{2}
\end{aligned}
$$


$0=\frac{\partial \mathrm{f}_{3}}{\partial \mathrm{a}_{5}}=\frac{\partial \mathrm{f}_{3}}{\partial \mathrm{a}_{9}}, \mathrm{f}_{3}=\sum_{\mathrm{i}=1}^{\mathrm{n}}\left(\mathrm{z}_{3}(\mathrm{i})-\mathrm{a}_{5}-\mathrm{a}_{9} \cdot \mathrm{i}\right)^{2}$

The solutions of eqs6 are therefore easily obtained (eqs7):

$$
\begin{aligned}
& a_{7}=\frac{n \sum_{i=1}^{n} x_{3}(i) \sin \left(a_{6} i\right)-\sum_{i=1}^{n} x_{3}(i) \sum_{i=1}^{n} \sin \left(a_{6} i\right)}{n \sum_{i=1}^{n} \sin \left(a_{6} i\right) \sin \left(a_{6} i\right)-\sum_{i=1}^{n} \sin \left(a_{6} i\right) \sum_{i=1}^{n} \sin \left(a_{6} i\right)} \\
& a_{3}=\left(\sum_{i=1}^{n} x_{3}(i)-a_{7} \sum_{i=1}^{n} \sin \left(a_{6} i\right)\right) / n \\
& a_{8}=\frac{n \sum_{i=1}^{n} \cos \left(a_{6} i\right) \cos \left(a_{6} i\right)-\sum_{i=1}^{n} \cos \left(a_{6} i\right) \sum_{i=1}^{n} \cos \left(a_{6} i\right)}{a_{4}=\left(\sum_{i=1}^{n} y_{3}(i)-a_{8} \sum_{i=1}^{n} \cos \left(a_{6} i\right)\right) / n} \\
& a_{5}=\left(\sum_{i=1}^{n} z_{3}(i)-a_{9} \cdot \sum_{i=1}^{n} i\right) / n \\
& \left.a_{9}=\frac{n \sum_{i=1}^{n} z_{3}(i) i-\sum_{i=1}^{n} z_{3}(i) \sum_{i=1}^{n} i}{n \sum_{i=1}^{n} i^{2}-\sum_{i=1}^{n} i \sum_{i=1}^{n} i} y_{3}(i) \sum_{6} a_{6} i\right)
\end{aligned}
$$

The complexity of finding the helix was reduced from a problem of optimum with 10 (eq3) or respectively 11 (eq5) unknown coefficients to a problem of optimum with 4 (eq3) or respectively 5 (eq4) unknown coefficients that must be determined.

The study was conducted with polymers that embedded seventeen (\#3, Table 1) or eighteen monomers (\#4, \#7, \#8, \#9, \#10, Table 2) to assure the reliability of the calculation with the available calculation power. The polymers of interest were drawn with HyperChem and their geometries were optimized with the Spartan program at Hartree-Fock [55] 6-31G* level of the theory [56].

$\mathrm{X}, \mathrm{Y}$, and $\mathrm{Z}$ coordinates resulted after optimization of the geometry were used to shape the helixes. These data were used as input data to identify the rotation and translation of the coordinates and respectively the coefficients of the helix. The graphical representation of these input data is presented in Fig. 1 where each triangle is made from the coordinates of a monomer. 
The above-presented equations were used to identify the optimum solution by using a guess value for the $\mathrm{a}_{6}$ coefficient and the same initial starting values for all other coefficients. The guess value for $\mathrm{a}_{6}$ coefficient was obtained by inspection of the graphical representations of the molecules.

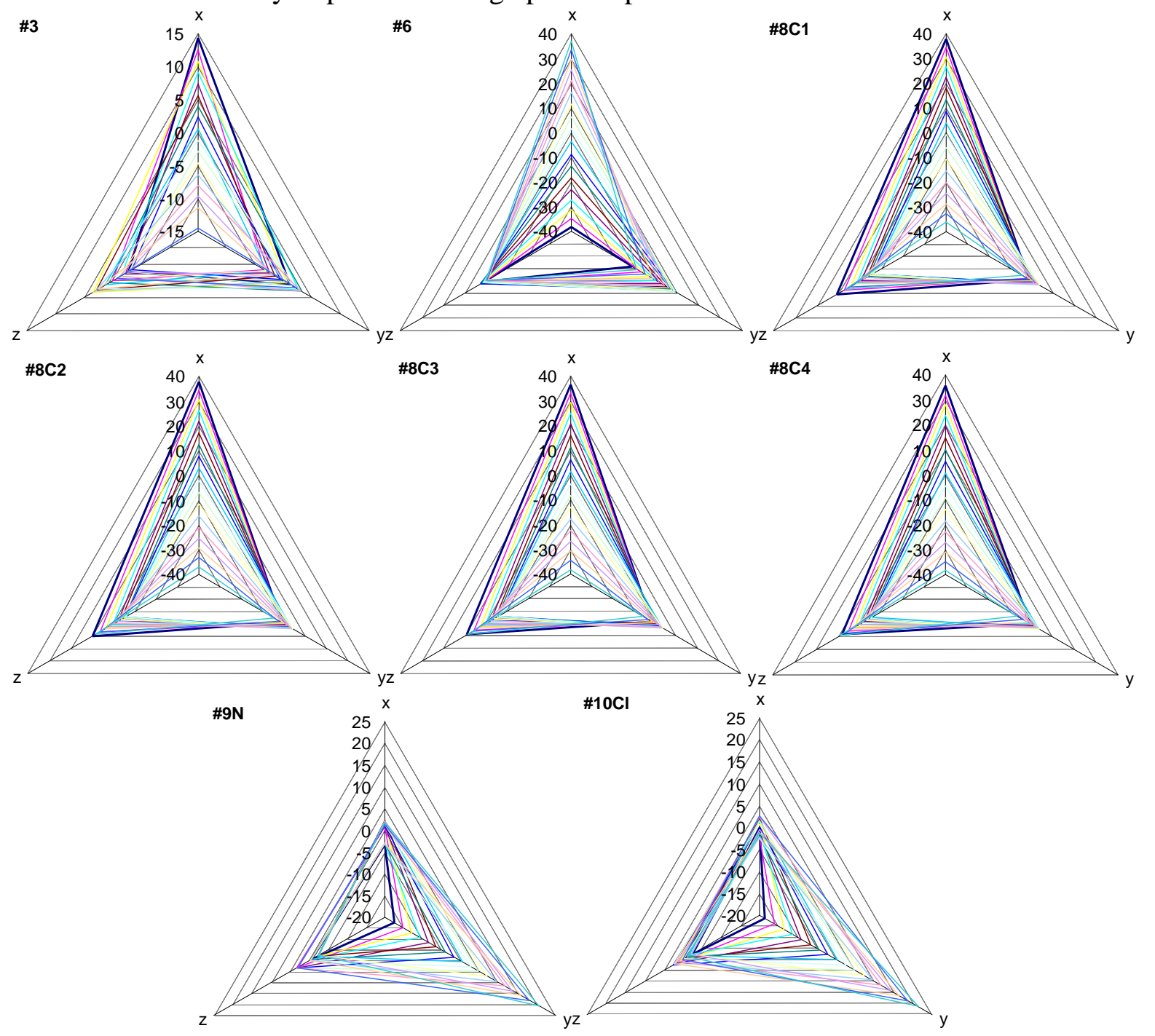

Fig. 1. Distribution of coordinates as resulted from geometry optimization.

Two different protocols were applied to calculate the values of interest:

- Protocol I was dedicated to the evaluation of the whole polymer. In the first step, the helix coefficient $\left(\mathrm{a}_{6}\right)$ was kept fixed and the values of the remaining coefficients were iterated to minimize the value of residuals until convergence. In the second step, the algorithm was applied again, starting with the final values obtained in the first step and the values of all coefficients (including helix coefficient $\mathrm{a}_{6}$ ) were iterated to minimize the residuals until convergence.

- Since usually at the end the geometrical constrains are different than in the middle of the polymer, the Protocol II was dedicated to the evaluation of a smaller inside portion of the polymer and was done by exclusion of one or two monomers from each end. The starting values in the calculation of 
the values of coefficients were the values obtained as optimum values at the end of the first protocol. The coefficients were iterated until convergence.

The input data were the atom coordinates. Thus, for \#3 the checkpoint was the double bonded oxygen, for \#6 the chlorine, for \#7 the carbon from methyl position. Four different checkpoints (C1 carbon connected with one fluorine atom, and C2, C3, and C4 - the other carbon atoms) were used for \#8. The checkpoint for \#9 was the nitrogen atom, while for the \#10 was chlorine atom.

\section{Convergence Analysis}

The pattern of convergence to the minimum value of residuals was different for the applied steps in the Protocol I. The starting values for the angular coefficients $\left(\mathrm{a}_{0}-\mathrm{a}_{2}\right)$ were 0.1 in all cases. The number of iterations until the convergence ranged between 26 and 41 (Fig. 2) when the value of $\mathrm{a}_{6}$ was fixed and was between 5 and 46 when all coefficients were calculated (Fig. 3).

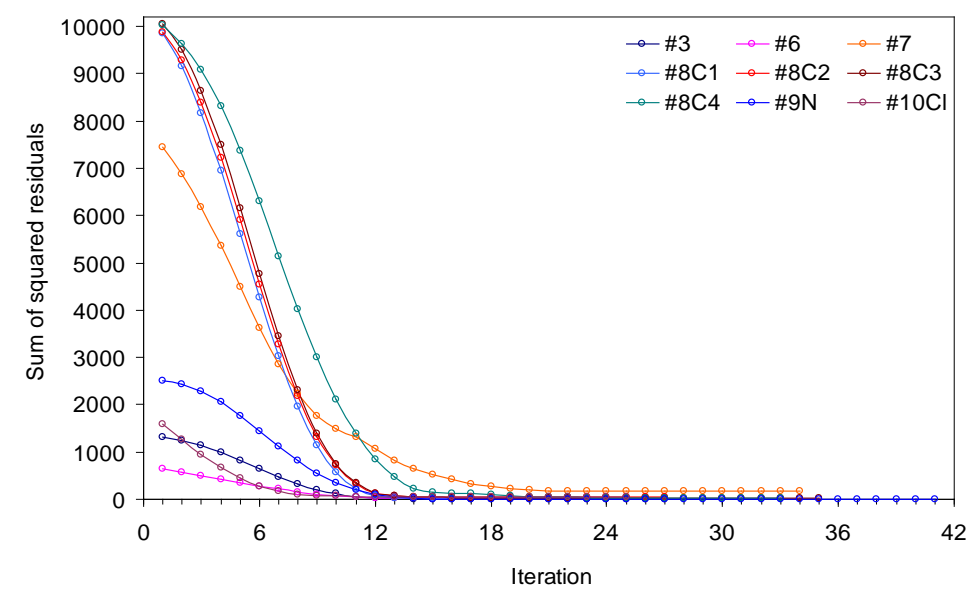

Fig. 2. Residuals convergence for helix coefficient fixed.

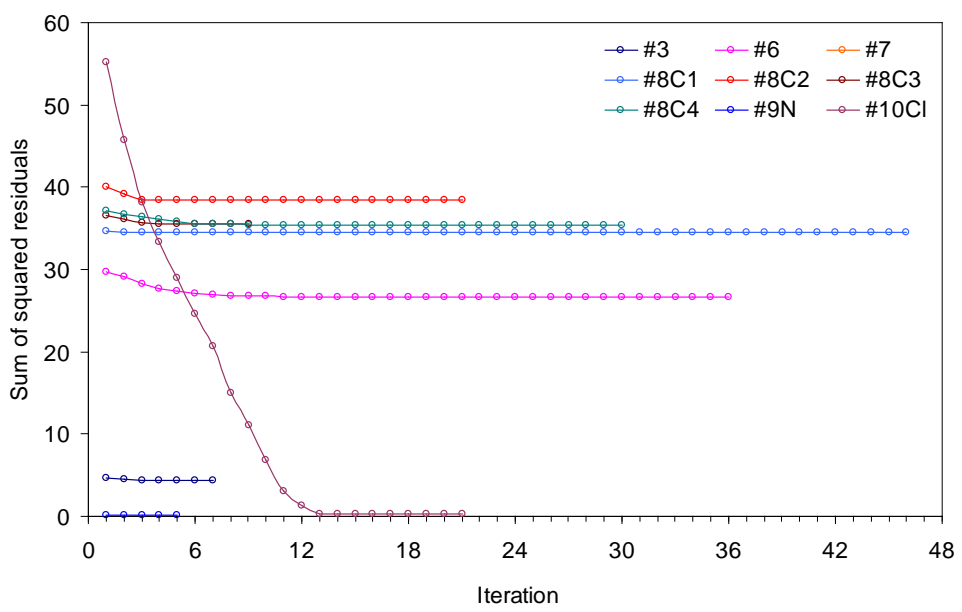

Fig. 3. Residuals convergence for helix coefficient also optimized. 
In the case with fixed value of $\mathrm{a}_{6}$, a similar (\#8C4 similar with all other \#8s, Fig. 2) and sometimes overlapping (\#8C1, \#8C2, and \#8C3) behavior was observed for polymer \#8 when different carbon atoms were imposed as a checkpoint. The residuals have the tendency to significant decrease until around the $12^{\text {th }}$ iteration and after this iteration, the changes in the values of residuals are small (Fig. 2).

The minimization of residuals in the second step mimic a change in a plateau with small differences between iteration on the same polymer with one exception represented by $\# 10 \mathrm{Cl}$ (Fig. 3). The residuals of the $\# 10 \mathrm{Cl}$ follow a change similar to the one observed in the first step with significant decrease until the $12^{\text {th }}$ iteration follows by a plateau where the changes are very small.

With no exception, the values of residuals reduced significantly at the end of the first step (Table 2). The highest reduction was observed for the \#9 polymer (its monomer contain a triple bond $-\mathrm{C} \equiv \mathrm{N}$ ) when the value of residual was 20,731 times lower at the end of the first step compared with the start value. The value of residuals at the end of the second step is less than 190 times as compared with the value of residuals at the end of the first step.

Table 2. The values of residuals and coefficients: first protocol

\begin{tabular}{|c|c|c|c|c|c|c|c|c|c|c|c|c|c|}
\hline & & residuals & $a_{0}$ & $a_{1}$ & $\mathrm{a}_{2}$ & $a_{3}$ & $\mathrm{a}_{4}$ & $a_{5}$ & $a_{6}$ & $\mathrm{a}_{7}$ & $\mathrm{a}_{8}$ & $\mathrm{a}_{9}$ & Iteration \\
\hline \multirow[t]{3}{*}{ \#3 } & start & 1316.371 & 0.100 & 0.100 & 0.100 & 0.450 & 0.435 & 1.480 & \multirow[t]{2}{*}{1.867} & 1.372 & 2.818 & -0.177 & 0 \\
\hline & end-1 & 4.720 & 1.538 & 0.923 & 1.521 & 0.059 & 0.061 & 16.081 & & 3.276 & 3.091 & -1.736 & 27 \\
\hline & end-2 & 4.410 & 1.545 & 0.843 & 1.527 & 0.026 & 0.028 & 16.082 & 1.876 & 3.264 & 3.103 & -1.736 & 7 \\
\hline \multirow[t]{3}{*}{ \#6 } & start & 10562.800 & \multicolumn{3}{|c|}{ Identical with \#3 } & -18.547 & -2.735 & -2.541 & \multirow[t]{2}{*}{0.155} & 25.095 & 2.612 & 0.319 & 0 \\
\hline & end-1 & 29.772 & 1.536 & -0.064 & 1.587 & -16.419 & 0.479 & -44.933 & & 25.049 & 1.022 & 4.624 & 37 \\
\hline & end-2 & 26.670 & 1.600 & $\mid-0.073$ & 1.580 & -13.788 & 0.535 & -44.939 & 0.165 & 22.452 & 1.088 & 4.633 & 36 \\
\hline \multirow[t]{3}{*}{ \#7 } & start & 7444.306 & \multicolumn{3}{|c|}{ Identical with \#3 } & 15.736 & -0.745 & -3.299 & \multirow[t]{2}{*}{0.194} & -27.304 & 2.934 & 0.374 & 0 \\
\hline & end-1 & 177.895 & 1.431 & -0.037 & 1.637 & 11.725 & -0.222 & -37.635 & & -22.925 & -1.005 & 4.074 & 34 \\
\hline & end-2 & 124.517 & 1.622 & \begin{tabular}{|l|}
-0.041 \\
\end{tabular} & 1.639 & 19.548 & 0.019 & -38.459 & 0.165 & -30.481 & -1.455 & 4.143 & 18 \\
\hline \multirow[t]{3}{*}{$\# 8 \mathrm{C} 1$} & start & 9846.996 & \multicolumn{3}{|c|}{ Identical with \#3 } & -8.205 & -1.086 & 6.253 & \multirow[t]{2}{*}{\begin{tabular}{|l|}
-0.172 \\
\end{tabular}} & -14.596 & -3.541 & -0.662 & 0 \\
\hline & end-1 & 34.633 & 1.363 & 1.214 & 1.361 & -11.097 & -0.186 & 44.230 & & -17.638 & -0.694 & -4.533 & 27 \\
\hline & end-2 & 34.452 & 1.420 & 1.214 & 1.417 & -11.884 & -0.142 & 44.256 & -0.168 & -18.362 & -0.577 & -4.535 & 46 \\
\hline \multirow[t]{3}{*}{ \#8C2 } & start & 9879.200 & \multicolumn{3}{|c|}{ Identical with \#3 } & -11.256 & -1.619 & 4.242 & \multirow[t]{2}{*}{-0.176} & -18.787 & -3.461 & -0.461 & 0 \\
\hline & end-1 & 40.091 & 1.463 & 1.143 & 1.490 & -10.456 & 0.551 & 43.714 & & -17.387 & 0.118 & -4.556 & 27 \\
\hline & end-2 & 38.377 & 1.589 & 1.142 & 1.607 & \begin{tabular}{|l|}
-12.553 \\
\end{tabular} & 0.598 & 43.790 & -0.165 & -19.356 & 0.214 & -4.562 & 21 \\
\hline \multirow[t]{2}{*}{ \#8C3 } & start & 10042.268 & \multicolumn{3}{|c|}{ Identical with \#3 } & -12.599 & -2.999 & 3.398 & \multirow[t]{2}{*}{-0.176} & -18.747 & -3.476 & -0.417 & 0 \\
\hline & end-1 & 36.508 & 1.487 & 1.139 & 1.483 & $\begin{array}{l}-10.503 \\
\end{array}$ & -0.109 & 42.449 & & -17.505 & -0.973 & -4.565 & 26 \\
\hline
\end{tabular}




\begin{tabular}{|c|c|c|c|c|c|c|c|c|c|c|c|c|c|}
\hline & end-2 & 35.542 & 1.585 & 1.131 & 1.575 & -12.112 & -0.024 & 42.526 & -0.167 & -19.058 & -0.850 & -4.571 & 9 \\
\hline \multirow[t]{3}{*}{ \#8C4 } & start & 10025.977 & \multicolumn{3}{|c|}{ Identical with \#3 } & -12.690 & -3.337 & 2.918 & \multirow[t]{2}{*}{-0.175} & -17.411 & -2.597 & -0.323 & 0 \\
\hline & end-1 & 37.168 & -1.578 & 2.051 & -1.573 & -10.648 & 0.127 & 41.182 & & -16.974 & 0.093 & -4.518 & 33 \\
\hline & end-2 & 35.331 & -1.464 & 2.057 & -1.475 & -12.656 & 0.175 & 41.234 & -0.164 & -18.981 & 0.019 & -4.523 & 30 \\
\hline \multirow[t]{3}{*}{ \#9N } & start & 2510.015 & 0.100 & 0.100 & 0.100 & 0.132 & 0.113 & 1.910 & \multirow[t]{2}{*}{2.103} & -2.119 & 1.882 & -0.215 & 0 \\
\hline & end-1 & 0.121 & 0.000 & -0.782 & 1.571 & 0.002 & 0.002 & 19.676 & & -3.221 & -3.212 & -2.220 & 41 \\
\hline & end-2 & 0.121 & 0.000 & -0.785 & 1.571 & 0.002 & 0.002 & 19.676 & 2.104 & -3.220 & -3.212 & -2.220 & 5 \\
\hline \multirow[t]{3}{*}{$\# 10 \mathrm{CL}$} & start & 2680.676 & \multicolumn{3}{|c|}{ Identical with \#3 } & 0.117 & 0.102 & 1.668 & \multirow[t]{2}{*}{2.103} & -1.120 & 2.215 & -0.196 & 0 \\
\hline & end-1 & 55.205 & -0.008 & -0.792 & 1.582 & -0.072 & -0.073 & 20.803 & & -1.723 & -1.564 & -2.328 & 30 \\
\hline & end-2 & 0.290 & -0.010 & -2.342 & 1.564 & 0.036 & 0.035 & 20.805 & 2.268 & -2.415 & -2.382 & -2.328 & 21 \\
\hline
\end{tabular}

end-1: the values obtained by minimizing the residuals when $\mathrm{a}_{6}$ is fixed;

end-2: the values obtained by minimizing the residuals when all coefficients are calculated

The lowest value of residuals is obtained at the end of the second step while the values of the coefficients of the helixes have generally the tendency to increase (see Table 2). However, for the \#7 and \#8 polymers, the coefficient of the helix decrease at the end of the second step compared with the value obtained at the end of the first step.

The smallest absolute value of the helix coefficient $\mathrm{a}_{6}$ when the first protocol was applied was of 0.155 (\#6, poly(1-chloro-trans-1-butenylene)) at the end of the first step and 0.164 (\#8C4, poly(1,4,4trifluoro-trans-1-butenylene)) at the end of the second step. The highest absolute value of the helix coefficient $\mathrm{a}_{6}$ was of 2.103 (\#9N - polyacrylonitrile and \#10Cl - polychlorotrifluoroethylene) at the end of the first step and 2.268 (\#10Cl - polychlorotrifluoroethylene) at the end of second step in this first protocol.

For the second protocol, the exclusion of the monomers from the ends of the polymer was investigated to identify the outliers of helix on the investigated polymers.

As expected, the behavior to the convergence to the minimum value of residuals was different when the second protocol was applied compared with the first protocol.

The number of iterations ranges from 7 to 80 when one monomer from each end of the polymer was excluded (the number of monomers in the polymers decreased with two, Fig. 4) and from 7 to 168 when two monomers from each end of the polymer were excluded (the number of monomers in the polymers decreased with four, Fig. 5). 


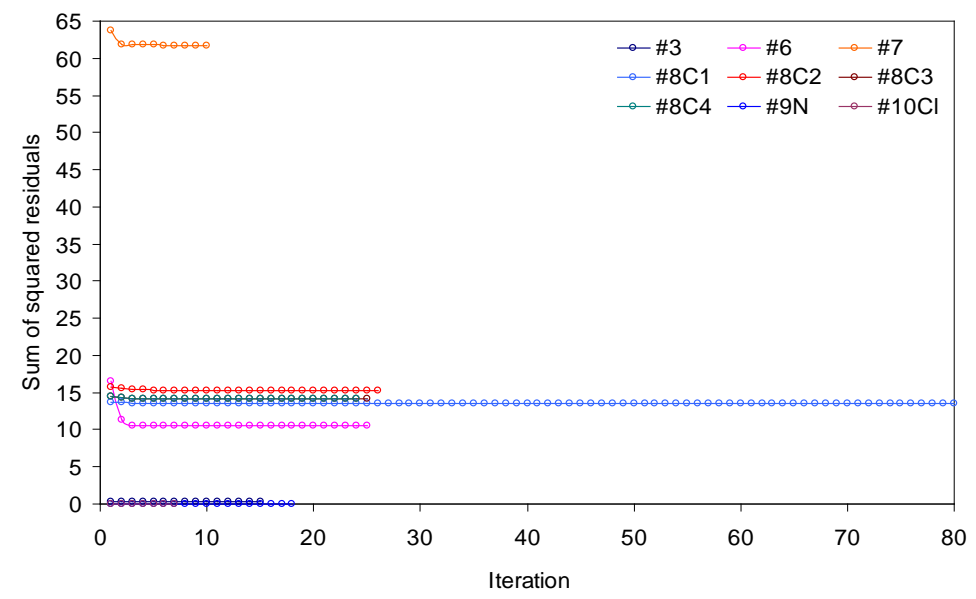

Fig. 4. Convergence of residuals for exclusion of one monomer from each end.

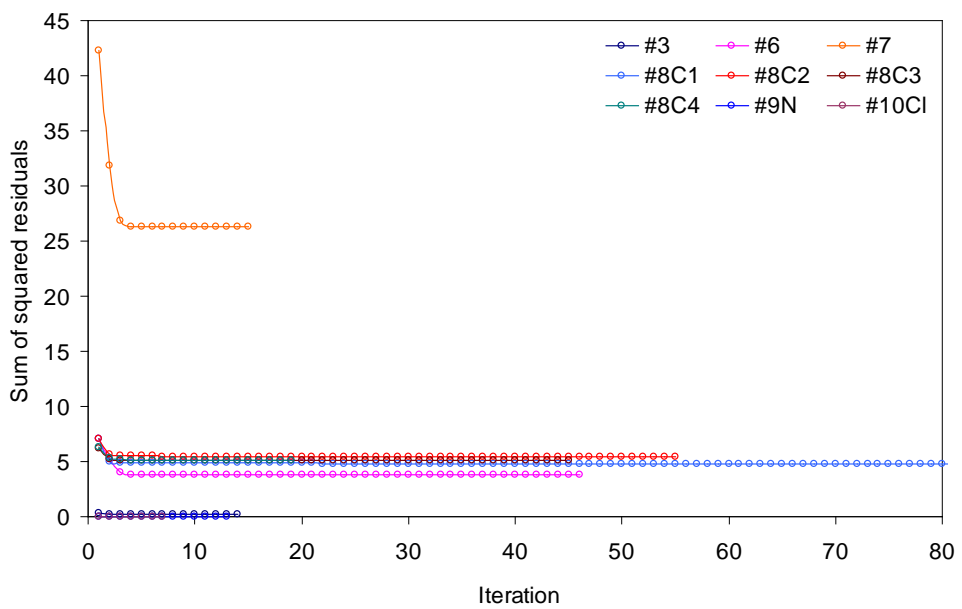

Fig. 5. Convergence of residuals for exclusion of two monomers from each end.

The changes in the residuals were smaller in the case of the second protocol compared with the first protocol. The minimization of residuals led to different values when one monomer is excluded compared with the case when two monomers are excluded (Table 3). The analysis of the values of residuals could let to the identification of the existence of outliers of the helix on the investigated polymers.

The values of residuals are similar after the exclusion of a monomer from each end of the polymer; as compared with the initial value, this indicates that the ended monomers are not outliers.

In two cases (\#9N \& \#10Cl) the residual data were lower than 0.1 and the values of the helix coefficients were different at a value of 0.001 when compared the exclusion of a monomer relative to the baseline value and identical for exclusion of one monomer or two monomers (see Table 3).

For \#9N, the exclusion of two monomers in each end of the polymer decrease the residuals 4 times (from 0.030 to 0.008) compared with the exclusion of one monomer, but in this case the ended monomers could not be considered outliers since the residuals are in all investigated cases very small.

In three investigated polymers (\#3, \#6, and \#7), one monomer from each end of the polymers could be considered as outlier of the helix since the value of residuals were three times lower compared with 
the values of residuals without any exclusion. Furthermore, the values of helix coefficient $\left(\mathrm{a}_{6}\right)$ are very closed for \#6 and \#7 to the start values and identical if one or two monomers at the end of each polymer were excluded (see Table 3).

Table 3. The values of residuals and coefficients: second protocol

\begin{tabular}{|c|c|c|c|c|c|c|c|c|c|c|c|c|c|}
\hline & \multirow{3}{*}{\begin{tabular}{r|} 
residuals \\
0.711
\end{tabular}} & & & & & & & & & & & \\
\hline & & & \multirow{2}{*}{\begin{tabular}{|l|}
$\mathrm{a}_{0}$ \\
1.545
\end{tabular}} & \multirow{2}{*}{\begin{tabular}{|l|}
$\mathrm{a}_{1}$ \\
0.843 \\
\end{tabular}} & \multirow{2}{*}{\begin{tabular}{|l|}
$\mathrm{a}_{2}$ \\
1.527
\end{tabular}} & \multirow{2}{*}{\begin{tabular}{|l|}
$\mathrm{a}_{3}$ \\
1.876
\end{tabular}} & \multirow{2}{*}{\begin{tabular}{|l|}
$\mathrm{a}_{4}$ \\
0.010
\end{tabular}} & \multirow{2}{*}{\begin{tabular}{|l|}
$\mathrm{a}_{5}$ \\
15.932
\end{tabular}} & \multirow{2}{*}{\begin{tabular}{|l|}
$\mathrm{a}_{6}$ \\
0.012
\end{tabular}} & \multirow{2}{*}{\begin{tabular}{|l}
$\mathrm{a}_{7}$ \\
3.255
\end{tabular}} & \multirow{2}{*}{\begin{tabular}{|l|}
$a_{8}$ \\
3.220 \\
\end{tabular}} & \multirow{2}{*}{\begin{tabular}{|l|}
$a_{9}$ \\
-1.711
\end{tabular}} & \multirow{2}{*}{$\begin{array}{r}\text { Iteration } \\
0\end{array}$} \\
\hline \#3 & start & & & & & & & & & & & & \\
\hline & excl-1 & 0.240 & 1.548 & 0.895 & 1.545 & 0.012 & 0.011 & 15.935 & 1.868 & 3.249 & 3.233 & -1.711 & 15 \\
\hline & excl-2 & 0.205 & 1.544 & 0.897 & 1.545 & 0.020 & 0.019 & 15.939 & 1.868 & 3.238 & 3.245 & -1.713 & 14 \\
\hline \multirow[t]{3}{*}{$\# 6$} & start & 28.438 & 1.600 & -0.073 & 1.580 & -13.525 & 1.626 & -45.839 & 0.165 & 22.133 & 1.481 & 4.728 & 0 \\
\hline & excl-1 & 10.547 & 1.603 & -0.075 & 1.539 & -13.363 & 0.615 & -45.687 & 0.166 & 21.978 & 2.873 & 4.716 & 25 \\
\hline & excl-2 & 3.764 & 1.605 & -0.075 & 1.506 & -13.094 & 0.666 & -46.281 & 0.166 & 21.673 & 4.258 & 4.782 & 46 \\
\hline \multirow[t]{3}{*}{ \#7 } & start & 167.269 & 1.622 & -0.041 & 1.639 & 19.883 & -2.457 & -40.294 & 0.165 & -30.886 & -0.518 & 4.337 & 0 \\
\hline & excl-1 & 61.771 & 1.625 & -0.041 & 1.756 & 20.026 & 0.253 & -39.945 & 0.164 & -31.030 & -4.198 & 4.296 & 10 \\
\hline & excl-2 & 26.278 & 1.623 & -0.046 & 1.850 & 20.329 & 0.411 & -41.187 & 0.164 & -31.383 & -6.314 & 4.423 & 15 \\
\hline \multirow[t]{3}{*}{ \#8C1 } & start & 19.043 & 1.420 & 1.214 & 1.417 & -11.900 & 0.509 & 44.871 & $\mid-0.168$ & -18.382 & -1.269 & -4.602 & 0 \\
\hline & excl-1 & 13.498 & 1.352 & 1.216 & 1.321 & -11.015 & -0.201 & 44.738 & -0.173 & -17.562 & -2.331 & -4.591 & 80 \\
\hline & excl-2 & 4.790 & 1.348 & 1.220 & 1.292 & -11.016 & -0.240 & 45.138 & -0.173 & -17.563 & -3.620 & -4.638 & 168 \\
\hline \multirow[t]{3}{*}{ \#8C2 } & start & 21.448 & 1.589 & 1.142 & 1.607 & -12.600 & 1.281 & 44.478 & -0.165 & -19.412 & -0.527 & -4.634 & 0 \\
\hline & excl-1 & 15.234 & 1.538 & 1.143 & 1.531 & -11.758 & 0.607 & 44.421 & $\mid-0.169$ & -18.597 & -1.481 & -4.629 & 26 \\
\hline & excl-2 & 5.441 & 1.524 & 1.147 & 1.494 & -11.574 & 0.582 & 44.913 & $\mid-0.170$ & -18.423 & -2.844 & -4.683 & 55 \\
\hline \multirow[t]{3}{*}{ \#8C3 } & start & 19.882 & 1.585 & 1.131 & 1.575 & -12.140 & 0.632 & 43.175 & -0.167 & -19.092 & -1.553 & -4.640 & 0 \\
\hline & excl-1 & 14.102 & 1.544 & 1.135 & 1.511 & -11.500 & -0.003 & 43.066 & -0.170 & -18.458 & -2.438 & -4.631 & 25 \\
\hline & excl-2 & 5.059 & 1.538 & 1.138 & 1.484 & -11.451 & 0.007 & 43.508 & -0.171 & -18.411 & -3.689 & -4.681 & 45 \\
\hline \multirow[t]{3}{*}{ \#8C4 } & start & 19.798 & -1.464 & 2.057 & -1.475 & -12.699 & 0.825 & 41.890 & -0.164 & -19.033 & -0.700 & -4.591 & 0 \\
\hline & excl-1 & 14.166 & -1.506 & 2.057 & -1.536 & -11.971 & 0.241 & 41.839 & -0.168 & -18.282 & -1.468 & -4.587 & 24 \\
\hline & excl-2 & 5.094 & -1.521 & 2.054 & -1.570 & -11.753 & 0.265 & 42.312 & $\mid-0.169$ & -18.061 & -2.711 & -4.639 & 19 \\
\hline \#9N & start & 0.037 & 0.000 & -0.785 & 1.571 & 0.007 & 0.007 & 19.630 & 2.104 & -3.218 & -3.223 & -2.215 & 0 \\
\hline
\end{tabular}




\begin{tabular}{|l|r|r|r|r|r|r|r|r|r|r|r|r|r|}
\hline & excl-1 & 0.030 & -0.002 & -0.785 & 1.571 & 0.006 & 0.006 & 19.629 & 2.103 & -3.219 & -3.224 & -2.215 & 18 \\
\hline excl-2 & 0.008 & -0.002 & -0.794 & 1.570 & 0.007 & 0.006 & 19.632 & 2.104 & -3.224 & -3.217 & -2.215 & 13 \\
\hline \#10Cl & start & 0.076 & -0.010 & -2.342 & 1.564 & 0.029 & 0.029 & 20.740 & 2.268 & -2.422 & -2.416 & -2.320 & 0 \\
\cline { 2 - 11 } & excl-1 & 0.056 & -0.010 & -2.337 & 1.568 & 0.028 & 0.028 & 20.740 & 2.267 & -2.422 & -2.418 & -2.320 & 7 \\
\hline
\end{tabular}

\section{Summary}

Helical geometries are natural in biological polymers structures as seen in DNA [5], RNA [57], or globular proteins [58]. The understanding of how this natural helical geometry occurs could guide the design of material at macro and nano-scale levels with specific desired uses and properties [59].

Our computational study showed that some of the investigated homopolymers have a good chance to stabilize as helical geometries and for these structures, several coefficients were calculated by minimization of residuals applying two different protocols. In our analysis, the polymer with the highest helix coefficient was the one formed by 18 polychlorotrifluoroethylene monomers with chlorine as checkpoint of the helix. Opposite, the polymer with the lowest helix coefficient was the one formed by 18 poly(1-chloro-trans-1-butenylene) monomers. The second protocol was applied to identify if the monomers (one or two) from the ends of the polymers are or not outliers of the helical geometry. In other words, this second protocol analyzed if helical geometry of investigated polymers are of 15/16 monomers instead of 17/18 monomers (a monomer in each end of the polymer was excluded) or respectively 13/14 (two monomers from each end of the polymer). The investigation of the helical geometry pattern with more monomers in the polymer could bring more sounds in the knowledge of their behavior.

\section{Acknowledgements}

This work was supported by a grant from the Romanian National Authority for Scientific Research and Innovation, CCCDI - UEFISCDI, project number 8/2015, acronym GEMNS (under the frame of the ERA-NET EuroNanoMed II European Innovative Research and Technological Development Projects in Nanomedicine).

\section{References}

[1] C.S. Hanes, The action of amylases in relation to the structure of starch and its metabolism in the plant. Parts IV-VII, New Phytologist 36 (1937) 101-141. https://doi.org/10.1111/j.14698137.1937.tb06906.x

[2] C.S. Hanes, The action of amylases in relation to the structure of starch and its metabolism in the plant. Parts I-III, New Phytologist 36 (1937) 189-239. https://doi.org/10.1111/j.14698137.1937.tb06913.x

[3] K. Freudenberg, E. Schaaf, G. Dumpert, T. Ploetz, Neue Ansichten über die Stärke, Naturwissenschaften 27 (1939) 850-853. https://doi.org/10.1007/BF01489430

[4] L. Pauling, R.B. Corey, Configuration of polypeptide chains, Nature, 168 (1951) 550-551. https://doi.org/10.1038/171737a0

[5] J.D. Watson, F.H.C. Crick, Molecular structure of nucleic acids: a structure for deoxyribose nucleic acid, Nature 171 (1953) 737-738. https://doi.org/10.1038/171737a0 
[6] H. Dong, J.Y. Shu, N. Dube, Y. Ma, M.V. Tirrell, K.H. Downing, T. Xu, 3-Helix micelles stabilized by polymer springs, J. Am. Chem. Soc. 134 (2012) 11807-11814. https://doi.org/10.1021/ja3048128

[7] Y. Chatani, T. Kobatake, H. Tadokoro, R. Tanaka, Structural studies of poly(ethylenimine). 2. Double-stranded helical chains in the anhydrate, Macromolecules 15 (1982) 170-176. https://doi.org/10.1021/ma00229a034

[8] C. Lambert, F. Koch, S.F. Völker, A. Schmiedel, M. Holzapfel, A. Humeniuk, M.I.S. Röhr, R. Mitric, T. Brixner, Energy Transfer Between Squaraine Polymer Sections: From Helix to Zigzag and All the Way Back, J. Am. Chem. Soc. 137 (2015) 7851-7861. https://doi.org/10.1021/jacs.5b03644

[9] R.W. Newberry, R.T. Raines, $n \rightarrow \pi^{*}$ interactions in poly(lactic acid) suggest a role in protein folding, Chemical Communications 49 (2013) 7699-7701. https://doi.org/10.1039/c3cc44317e

[10] L. Jäntschi, S.D. Bolboacă, Study of geometrical shaping of linear chained polymers stabilized as helixes, Studia Universitatis Babes-Bolyai Chemia LXI (2016) 131-145.

[11] J.A. Di Palma, M.B. Cleveland, J. McGowan, J.L. Herrera, A randomized, multicenter comparison of polyethylene glycol laxative and tegaserod in treatment of patients with chronic constipation, The American Journal of Gastroenterology 102 (2007) 1964-1971. https://doi.org/10.1111/j.1572-0241.2007.01365.x

[12] A. Kolate, D. Baradia, S. Patil, I. Vhora, G. Kore, A. Misra, PEG - A versatile conjugating ligand for drugs and drug delivery systems, J. Controlled Release 192 (2014) 67-81. https://doi.org/10.1016/j.jconrel.2014.06.046

[13] Z. Zhang, Y. Zhao, X. Meng, D. Zhao, D. Zhang, L. Wang, C. Liu, A Simple Zn ${ }^{2+}$ complex-based composite system for efficient gene delivery, PLoS One 11 (2016) e0158766. https://doi.org/10.1371/journal.pone.0158766

[14] X. Ping, K. Jiang, S.-Y. Lee, J.-X. Cheng, X. Jin, PEG-PDLLA micelle treatment improves axonal function of the corpus callosum following traumatic brain injury, J Neurotrauma 31 (2014) 1172-1179. https://doi.org/10.1089/neu.2013.3147

[15] V.N. Bharadwaj, J. Lifshitz, P.D. Adelson, V.D. Kodibagkar, S.E. Stabenfeldt, Temporal assessment of nanoparticle accumulation after experimental brain injury: Effect of particle size, Sci. Rep. 6 (2016) 29988. https://doi.org/10.1038/srep29988

[16] A. Lasek-Duriez, M.C. Castelain, P. Modiano, Allergic contact dermatitis due to methoxy PEG-22 dodecyl glycol present in a cosmetic cold cream. Annales de Dermatologie et de Vénéréologie 140 (2013) 528-530. https://doi.org/10.1016/j.annder.2013.01.427

[17] Current EU approved additives and their E Numbers. UK Government - Food Standards Agency. Retrieved 21 October 2016.

[18] O. Yemul, T. Imae, Synthesis and characterization of poly(ethyleneimine) dendrimers, Colloid. Polym. Sci. 286 (2008) 747-752. https://doi.org/10.1007/s00396-007-1830-6

[19] K. Kim, B. Bae, Y.J. Kang, J.-M. Nam, S. Kang, J.-H. Ryu, Natural polypeptide-based supramolecular nanogels for stable noncovalent encapsulation, Biomacromolecules 14 (2013) 3515-3522. https://doi.org/10.1021/bm400846h 
[20] Y. Li, M. Guo, Z. Lin, M. Zhao, M. Xiao, C. Wang, T. Xu, T. Chen, B. Zhu, Polyethylenimine-functionalized silver nanoparticle-based co-delivery of paclitaxel to induce HepG2 cell apoptosis. Int. J Nanomedicine 11 (2016) 6693-6702. https://doi.org/10.2147/IJN.S122666

[21] X. Zhao, H. Cui, W. Chen, Y. Wang, B. Cui, C. Sun, Z. Meng, G. Liu, Morphology, structure and function characterization of PEI modified magnetic nanoparticles gene delivery system, PLoS One 9 (2014) e98919. https://doi.org/10.1371/journal.pone.0098919

[22] J.D. Ziebarth, D.R. Kennetz, N.J. Walker, Y. Wang, Structural comparisons of PEI/DNA and PEI/siRNA complexes revealed with molecular dynamics simulations, J Phys. Chem. B 121 (2017) 1941-1952. https://doi.org/10.1021/acs.jpcb.6b10775

[23] M.M. Azevedo, P. Ramalho, A.P. Silva, R. Teixeira-Santos, C. Pina-Vaz, A.G. Rodrigues, Polyethyleneimine and polyethyleneimine-based nanoparticles: novel bacterial and yeast biofilm inhibitors, J Medical Microbiology 63 (2014) 1167-1173. https://doi.org/10.1099/jmm.0.0696090

[24] N. Sahiner, S. Sagbas, M. Sahiner, R.S. Ayyala, Polyethyleneimine modified poly(Hyaluronic acid) particles with controllable antimicrobial and anticancer effects. Carbohydr. Polym. 159 (2017) 29-38. https://doi.org/10.1016/j.carbpol.2016.12.024

[25] O. Martin, L. Avérous, Poly(lactic acid): plasticization and properties of biodegradable multiphase systems, Polymer 42 (2001) 6209-6219. https://doi.org/10.1016/S00323861(01)00086-6

[26] R. Mehta, V. Kumar, H. Bhunia, S.N. Upadhyay, Synthesis of poly(lactic acid): a review. J Macromolecular Sci.: Part C: Polymer Rev. 45 (2005) 325-349. https://doi.org/10.1080/15321790500304148

[27] P. Gentile, V. Chiono, I. Carmagnola, P.V. Hatton, An overview of Poly(lactic-coglycolic) Acid (PLGA)-based biomaterials for bone tissue engineering, Int. J Mol. Sci. 15 (2014) 3640-3659. https://doi.org/10.3390/ijms15033640

[28] J.S. Fernandes, R.L. Reis, R.A. Pires, Wetspun poly-L-(lactic acid)-borosilicate bioactive glass scaffolds for guided bone regeneration. Mater. Sci. Eng.: C Mater. Biological Appl. 71 (2017) 252-259. https://doi.org/10.1016/j.msec.2016.10.007

[29] N. Saito, K. Takaoka, New synthetic biodegradable polymers as BMP carriers for bone tissue engineering, Biomaterials 24 (2003) 2287-2293. https://doi.org/10.1016/S01429612(03)00040-1

[30] R. Mehta, V. Kumar, H. Bhunia, S.N. Upadhyay, Synthesis of poly(lactic acid): a review, J $\begin{array}{llllll}\text { Macromolecular } & \text { Sci. } & \text { Polymer } & \text { Rev. } & 45 & \text { (2005) 325-349. }\end{array}$ https://doi.org/10.1080/15321790500304148

[31] C. Chen, G. Lv, C. Pan, M. Song, C. Wu, D. Guo, X. Wang, B. Chen, Z. Gu, Poly(lactic acid) (PLA)-based nanocomposites-a novel way of drug-releasing, Biomedical Materials 2 (2007) L1-4. https://doi.org/10.1088/1748-6041/2/4/L01

[32] J. Li, C. Chen, X. Wang, Z. Gu, B. Chen, Novel Strategy to Fabricate PLA/Au nanocomposites as an efficient drug carrier for human leukemia Cells in Vitro, Nanoscale Research Letters 6 (2011) 29. 
[33] X. Liu, Y. Xu, Z. Wu, H. Chen, Poly(N-vinylpyrrolidone)-modified surfaces for biomedical applications, Macromolecular Bioscience $13 \quad$ (2013) 147-154. https://doi.org/10.1002/mabi.201200269

[34] A.N. Kuskov, P.P. Kulikov, A.V. Goryachaya, M.N. Tzatzarakis, A.O. Docea, K. Velonia, M.I. Shtilman, A.M. Tsatsakis, Amphiphilic poly-N-vinylpyrrolidone nanoparticles as carriers for non-steroidal, anti-inflammatory drugs: In vitro cytotoxicity and in vivo acute toxicity study. Nanomedicine: Nanotechnology, Biology and Medicine 13 (2017) 1021-1030. https://doi.org/10.1016/j.nano.2016.11.006

[35] X. Yao, C. Xie, W. Chen, C. Yang, W. Wu, X. Jiang, Platinum-incorporating Poly(Nvinylpyrrolidone)-poly(aspartic acid) pseudoblock copolymer nanoparticles for drug delivery, Biomacromolecules 16 (2015) 2059-2071. https://doi.org/10.1021/acs.biomac.5b00479

[36] R.B. Fox, Glass transition temperature for selected polymers. In: Haynes W.M. (Ed). CRC Handbook of Chemistry and Physics, 97th Edition, 13-10, 2017 CRC Press Taylor \& Francis Group, Boca Raton, FL, USA.

[37] H. Finkentscher, C. Heuck, DE Patent 654989, Verfahren zur Herstellung von Polymerisationprodukten, Anmeldetag 18.2.1930

[38] M. Schwartz, Encyclopedia of materials, parts, and finishes. (2nd ed.) CRC Press, Boca Raton, Florida, 2002.

[39] M.S.A. Rahaman, A.F. Ismail, A. Mustafa, A review of heat treatment on polyacrylonitrile $\begin{array}{llllll}\text { fiber, } & \text { Polym. } & \text { Degrad. } & \text { Stab. } & 92 & \text { (2007) }\end{array}$ https://doi.org/10.1016/j.polymdegradstab.2007.03.023

[40] S. Nunna, M. Naebe, N. Hameed, B.L. Fox, C. Creighton, Evolution of radial heterogeneity in polyacrylonitrile fibres during thermal stabilization: An overview, Polym. Degrad. Stab. 136 (2017) 20-30. https://doi.org/10.1016/j.polymdegradstab.2016.12.007

[41] L. Zhang, A. Aboagye, A. Kelkar, C. Lai, H. Fong, A review: carbon nanofibers from electrospun polyacrylonitrile and their applications, J Mater. Sci. 49 (2014) 463-480. https://doi.org/10.1007/s10853-013-7705-y

[42] M. Bourourou, M. Holzinger, F. Bossard, F. Hugenell, A. Maaref, S. Cosnier, Chemically reduced electrospun polyacrilonitrile-carbon nanotube nanofibers hydrogels as electrode material $\begin{array}{llllll}\text { for bioelectrochemical applications, } & \text { Carbon } 87 & \text { (2016) 233-238. }\end{array}$ https://doi.org/10.1016/j.carbon.2015.02.026

[43] W. Han, S. Dong, B. Li, L. Ge, Preparation of polyacrylonitrile- based porous hollow carbon microspheres, Colloids and Surfaces A: Physicochemical and Engineering Aspects 520 (2017) 467-476. https://doi.org/10.1016/j.colsurfa.2017.02.009

[44] S. Koutsonas, Electrical conductivity of degraded polyacrylonitrile powder by microwave irradiation for supercapacitor devices or other mobile applications, Mater. Letter. 193 (2017) 203205. https://doi.org/10.1016/j.matlet.2017.02.001

[45] D. Liu, H. Chen, P. Yin, N. Ji, G. Zong, R. Qu, Synthesis of polyacrolonitrile by singleelectron transfer-living radical polymerization using $\mathrm{Fe}(0)$ as catalyst and its absorption properties after modification, J Polymer Sci. Part A: Polymer Chem. 49 (2011) 2916-2923. https://doi.org/10.1002/pola.24727 
[46] T. Nakajima, H. Groult, Fluorinated materials for energy conversion. Elsevier. 2005, pp. 472. ISBN 978-0-08-044472-7.

[47] R. Winter, A Consumer's Dictionary of Household, Yard and Office Chemicals: Complete Information About Harmful and Desirable Chemicals Found in Everyday Home Products, Yard Poisons, and Office Polluters. iUniverse. 2007, p. 255.

[48] F. Cardarelli, Materials handbook: a concise desktop reference. Springer. 2008, pp. 708709.

[49] T. Hongxiang, Overview of the development of the fluoropolymer indus. Applied Sciences 2 (2012) 496-512. https://doi.org/10.3390/app2020496

[50] M.G. Hosseini, H. Teymourinia, A. Farzaneh, S. Khameneh-asl, Evaluation of corrosion, mechanical and structural properties of new Ni-W-PCTFE nanocomposite coating, Surf. Coat. Technol. 298 (2016) 114-120. https://doi.org/10.1016/j.surfcoat.2016.04.060

[51] R.V. Mazurenko, S.M. Makhno, G.M. Gunya, P.P. Gorbyk, Effect of dispersion of copperiodide particles on the electrical properties of composites based on polychlortrifluoroethylene, $\begin{array}{lllll}\text { Metallofizika i } & \text { Noveishie } & \text { Tekhnologii } & \text { (2016) }\end{array}$ https://doi.org/10.15407/mfint.38.05.0647

[52] T.P. O'Brien, G.M. McNally, W.R. Murphy, B.G. Millar, G.S. Garrett, A.H. Clarke, R.P. McGinley, Assessing the thermoformability of high-performance polymers for use in medical packaging applications. 66th Annual Technical Conference of the Society of Plastics Engineers, Plastics Encounter at ANTEC 2008; Milwaukee, WI; United States; 4 May 2008 through 8 May 2008; Technical Papers, Regional Technical Conference - Society of Plastics Engineers Volume 2, 2008, 963-96.

[53] R.M.V. Alves, S.B.M. Jaime, M.R. Goncalves, R.W. Suzuki, Plastic and glass packages for pharmaceutical products: Evaluation of light barrier properties, Revista de Ciencias Farmaceuticas Basica e Aplicada 29 (2008) 167-178.

[54] J. Gardiner, Fluoropolymers: origin, production, and industrial and commercial applications, Aust. J. Chem. 68 (2015) 13-22. https://doi.org/10.1071/CH14165

[55] J.C. Slater, The electronic structure of atoms - the hartree-fock methods and correlations, Reviews of Modern Physics 35 (1963) 484-487. https://doi.org/10.1103/RevModPhys.35.484

[56] R. Ditchfield, W.J. Hehre, J.A. Pople, Self-consistent molecular-orbital methods. IX. An extended gaussian-type basis for molecular-orbital studies of organic molecules, J Chem. Phys. 54 (1971) 724-728. https://doi.org/10.1063/1.1674902

[57] N. Safaee, A.M. Noronha, D. Rodionov, G. Kozlov, C.J. Wilds, G.M. Sheldrick, K. Gehring, Structure of the parallel duplex of poly(A) RNA: evaluation of a 50 year-old prediction, Angewandte Chemie International Edition $52 \quad$ (2013) 10370-10373. https://doi.org/10.1002/anie.201303461

[58] J.W. Prothero, Correlation between the distribution of amino acids and alpha helices. Biophysical Journal 6 (1966) 367-370. https://doi.org/10.1016/S0006-3495(66)86662-6

[59] M. Bassas-Galia, S. Follonier, M. Pusnik, M. Zinn, 2 - Natural polymers: a source of inspiration. bioresorbable polymers for biomedical applications. From fundamentals to translational medicine, Woodhead Publishing, Elsevier Ltd. 2017, pp. 31-64. https://doi.org/10.1016/B978-0-08-100262-9.00002-1 